DOI 10.15826/B978-5-7996-3073-7.7

\author{
Yulia Solovieva \\ Luis Quintanar \\ Autonomous University of Tlaxcala, \\ Tlaxcala, Mexico
}

\title{
Qualitative neuropsychological assessment of children
}

Abstract. Qualitative assessment is an essential method of clinical neuropsychology. According to conceptual bases of historical and cultural neuropsychology, qualitative assessment should include analysis of the neuropsychological syndrome in each particular case. The paper presents the method for qualitative neuropsychological assessment created for children in Mexico for Spanish-speaking population aged 5-12 with the help of the Scheme for "Brief Neuropsychological Assessment for Children". The structure and the ways for analysis of clinical data are included. The conclusions mention the possible applications of this instrument.

Keywords: neuropsychological assessment, child neuropsychology, qualitative approach, brain mechanisms, Luria’s approach.

Introduction. From the point of view of the qualitative clinical approach in neuropsychology, consideration of complex systems as a basis of brain functional representation of a psychological process is one of the key methodological principles $[1,2]$. Historical-cultural neuropsychology offers functional analysis of brain mechanisms, which might help to determine the clinical features of syndrome in children of preschool and school age. Instead of traditional psychometrical interpretation of difficulties, qualitative analysis of brain cortical and subcortical mechanisms permits us to characterize the syndrome as a whole and not as isolated quantification of cognitive processes. Such information can be obtained through qualitative analysis of errors and particular features observed during the implementation of neuropsychological assessment $[3,4]$. In order to evaluate the functional state of brain mechanisms, neuropsychological qualitative analysis frequently includes tasks for evaluation of programming and control, phonemic and kinesthetic integration, motor sequential organization, spatial functions of synthesis and 
analyses and retention in different modalities and the phone of cortical non-specific activation. Different methods and levels of analysis might be useful for neuropsychological qualitative assessment. Specific tasks and items should be created and tested according to specific cultural and linguistic features of each population.

Materials and methods. Neuropsychological assessment was accomplished according to Luria's theory and its later development in modern child neuropsychology $[3,4]$. Special instruments were developed for Spanish-speaking child population aged 5-12 [5]. The Scheme of Brief Neuropsychological Assessment for children includes special tasks for the following neuropsychological aspects (brain mechanisms related to three functional blocks according to Luria's proposal): the first functional block related to general brain cognitive and emotional activation and subcortical structures; the second functional block related to processing and conservation of information of various modalities and to cortical posterior zones; and the third functional block related to programming and control and to anterior cortical zones (anterior zones).

The objective of our Scheme for Neuropsychological Assessment is to determine a positive or negative state during action fulfillment of neuropsychological mechanisms as functional elements during execution of actions by children.

The structure of the Scheme for Assessment includes the following parts and items:

1) Kinesthetic analysis and synthesis - the $2^{\text {nd }}$ functional block (tactile recognition of common objects; repetition of syllables with close articulations; poses of fingers; reproduction of poses of fingers with closed eyes);

2) Phonemic analysis and synthesis - the $2^{\text {nd }}$ functional block (repetition of words with opposite phonemes; repetition of syllables with opposite phonemes; identification of opposite sounds in series);

3) Motor sequential organization of actions and movements - the $3^{\text {rd }}$ functional block (alternate coordination of hands; alternate coordination of fingers; copy and continuation of a graphic sequence);

4) Spatial analyses and synthesis - the $2^{\text {nd }}$ functional block (copy of a house; free drawing of girl and boy; comprehension of complex grammatical structures); 
5) Visuo-verbal retention - the $2^{\text {nd }}$ functional block (copy and evocation of letters; copy and evocation of complex figures);

6) Audio-verbal retention - the $2^{\text {nd }}$ functional block (direct repetition of series of words and sentences; involuntary, voluntary and retarded evocation of series of words and sentences);

7) Programming and control - the $3^{\text {rd }}$ functional block (verbal selective instructions presented as a game in situation with a conflict);

8) General brain tonic activation - the $1^{\text {st }}$ functional block (general observation of the whole procedure of execution of all tasks; task of marking of the same word with lines in a short verbal text).

The qualitative analyses of the types of mistakes made by children during the task fulfillment, observations of the whole procedure of test application and of children's behavior enable us to show the functional positive or negative state of the above-mentioned brain mechanisms in children of pre-school and school age. The Scheme might be applied in individual sessions lasting 40-60 min. The same task may be significant not only for one but for various functional mechanisms. The objective of qualification of criteria of errors consists in finding the relation between the types of errors and features of positive or negative functioning of each brain mechanism and qualitatively compare the difficulties and success during the execution of these tasks.

Conclusion. We are convinced that neurological, psychiatric and psychometric assessment may not substitute qualitative neuropsychological assessment in cases of developmental difficulties and learning disabilities. The objectives of quantitative and qualitative clinic differ essentially and the psychometric approach alone in cases of attention doesn't provide the necessary information for clinical judgement from the neuropsychological point of view. For a neuropsychological analysis of a syndrome within A. R. Luria's neuropsychological tradition, weak functional mechanisms should be established as a result of analysis of errors according to the qualitative criteria. Specific errors and difficulties should be found and systematized according to their relation to each brain unit and mechanism. Such way of reasoning helps to understand the cause of difficulties, provide recommendations and create a correction program which will enhance the psychological development of a child. 
1. Luria A. R. Brain in action. Mexico: Ediciones Roca, 1989.

2. Leont'ev A.N. Psihologicheskie osnovy razvitiya rebenka i obucheniya (sbornik). M. : Smysl, 2009.

3. Akhutina T. V., Pilayeva N. M. Overcoming learning disabilities. A Vigotskian-Lurian neuropsychological approach. Cambridge: Cambridge University Press, 2012.

4. Glozman J. Nejropsihologiya detskogo vozrasta. M. : Akademiya, 2009.

5. Solovieva Yu., Quintanar L. Brief Neuropsychological Assessment for children: Puebla. Mexico: Puebla Autonomous University, 2017. 